\title{
Infecciones en la mujer embarazada transmisibles al feto
}

\author{
KATIA ABARCA V. ${ }^{1}$
}

\section{Vertically transmitted infections in the pregnant woman}

Pregnant woman is exposed to a high range of infections, not only bacterial, but also viral and parasitic. Many of these infections may produce severe diseases in the fetus and newborn child. The mother to child transmission can occur during pregnancy, during labor and in the postpartum period. This article summarizes some preventive strategies of proven efficacy against some of these infections: vaccination of the childbearing age women against rubella, varicella, hepatitis B and diphtheria-tetanus, and vaccination against influenza during pregnancy; screening tests of infections that have effective preventive measures (routine serologic test for HIV and syphilis, serologic test for hepatitis B in non-vaccinated women) and some strategies to prevent toxoplasmosis. The article also reviews with some detail the following infections when they occur during pregnancy: Group B $\beta$ hemolytic Streptococcus, Listeria monocytogenes, Chlamydia trachomatis, genital herpes, chickenpox and B19 parvovirus. For each of these infections, epidemiological aspects are mentioned, as well as the timing and frequency of vertical transmission, risks for mother and child, therapy for mother infection and, mainly, preventive strategies for reducing vertical transmission.

Key words: Pregnancy; Vertically transmitted infections; Group B streptococci; herpes simplex; Listeria monocytogenes; Chlamydia trachomatis; Varicella; Parvovirus B19.

Son numerosas las infecciones que pueden ocurrir durante el embarazo y que significan un riesgo para el feto o recién nacido ${ }^{1}$. La Tabla 1 resume los principales agentes causantes de estas infecciones.

La transmisión de estas infecciones de la madre al hijo puede ocurrir:

- Durante el embarazo, principalmente por vía transplacentaria y mucho menos frecuentemente por vía ascendente, dando lugar en el niño a infecciones congénitas.

- Durante el parto, a través del contacto con secreciones infectadas en el canal del parto, dando origen a infecciones perinatales.

- Después del parto, a través de la lactancia materna o contacto con secreciones maternas, dando origen a infecciones post-natales.

Estas tres vías de transmisión constituyen la llamada transmisión vertical de infecciones.

Considerando lo extenso del tema, esta revisión sólo se referirá a algunas de estas infeccio- nes, seleccionando principalmente aquellas que cuentan con terapia específica o profilaxis medicamentosa.

\section{Prevención}

Existen diversas medidas preventivas para las infecciones de la mujer embarazada con riesgo para el hijo, que han sido implementadas en distintos países.

La primera línea de prevención la constituye la vacunación de la mujer antes del embarazo. Idealmente toda mujer en edad fértil debería estar vacunada contra rubéola*, varicela (en caso de historia o serología negativa), hepatitis B y difteria-tétanos (refuerzos cada 10 años). Además, por el mayor riesgo materno de complicaciones, se recomienda la vacunación contra la influenza durante el embarazo.

Otras medidas preventivas ${ }^{2}$ que han sido implementadas en Chile, con distinto grado de

Unidad de Infectología Servicio de Pediatría, Hospital Clínico Pontificia Universidad Católica de Chile.

* En Chile, la vacunación rutinaria contra rubéola se inició el año 1990 y los años siguientes el refuerzo en enseñanza básica, además se realizó una campaña en mujeres entre 10 y 29 años en 1999. De esta forma, pueden considerarse con dos dosis las mujeres nacidas a partir de 1983 y con una dosis, las nacidas desde 1970.

E-mail: katia@med.puc.cl 
cumplimiento, son: la serología para VIH durante el embarazo con institución de profilaxis con AZT a la mujer gestante infectada por VIH y a su hijo; el VDRL en primer y tercer trimestre del embarazo, con terapia y seguimiento de los casos positivos según normas nacionales; y la profilaxis contra Streptococcus agalactiae, que se revisará más adelante.

Entre las medidas de prevención de ETS, se encuentran la realización de serología contra hepatitis B (HBsAg) en mujeres no vacunadas ${ }^{2}$, en el primer control de embarazo repitiéndola si es negativa y la mujer se considera de riesgo (portadora de VIH, múltiples parejas sexuales, drogadicción endovenosa, presencia de otras ETS); y evaluación de vaginosis bacteriana en mujeres con antecedentes de parto prematuro.

Como medida preventiva contra toxoplasmosis, algunos países efectúan serología de screening en el embarazo, haciendo recomendaciones de prevención en las mujeres seronegativas; otra estrategia es dar recomendaciones universales de prevención a la mujer embarazada. Estas recomendaciones son:

- Consumir carne bien cocida.

- Pelar o lavar cuidadosamente frutas y verduras.

Tabla 1. Principales agentes causantes de infecciones en la mujer embarazada con riesgo para el hijo

\begin{tabular}{l}
\hline Enfermedades de transmisión sexual (ETS) \\
\hline Bacterianas \\
Chlamydia trachomatis \\
Treponema pallidum \\
Ureaplasma urealyticum \\
Vaginosis bacteriana \\
Virales \\
Hepatitis B \\
Hepatitis C \\
Herpes genital (VHS-2) \\
Papilomavirus \\
Virus de inmunodeficiencia humana
\end{tabular}

Enfermedades consideradas no venéreas

Bacterianas
Escherichia coli
Streptococcus agalactiae
Listeria monocytogenes
Virales
Citomegalovirus (CMV)
Parvovirus
Rubéola
Varicela
Parasitarias
Toxoplasma gondii

- Lavar las manos, cocina y utensilios de cocina después de manipular carne cruda, frutas y verduras.

- Evitar todo contacto con heces de gato. Si es absolutamente necesario que la embarazada realice estas labores, debe hacerlo con guantes y con cuidadoso lavado posterior de manos.

- No alimentar gatos con carne cruda.

- Mantener los gatos dentro de la casa.

- No adquirir gatos durante el embarazo.

- Uso de guantes al contacto con tierra, por ej. al realizar labores de jardinería.

\section{Streptococcus agalactiae ( $\beta$ hemolítico grupo B)}

La portación de SGB en embarazadas varía entre 10 y $30 \%$ en las distintas series. Se estima que entre 50 y $70 \%$ de los hijos de madres portadoras se colonizan por esta bacteria y $1,2 \%$ desarrolla sepsis neonatal. La tasa de sepsis por SGB se estima en 3,8/1.000 RN vivos, si no se realizan medidas de prevención.

Existen dos grandes estrategias de prevención de la infección por SGB: administrar antimicrobianos (generalmente ampicilina) durante el trabajo de parto a las mujeres de alto riesgo o a las mujeres colonizadas; para esto último se requiere realizar cultivo, idealmente vaginal y rectal, durante el tercer trimestre del embarazo ${ }^{3}$.

Las mujeres con alto riesgo son aquellas con parto prematuro, bacteriuria por SGB durante el embarazo, antecedente de RN con sepsis por SGB, fiebre durante el trabajo de parto y rotura prematura de membranas (RPM) de más de 12 horas.

Sin embargo, con la estrategia de tratar sólo a las mujeres con alto riesgo no es posible controlar el problema, dado que 85 a $90 \%$ de las mujeres gestantes carecen de estos factores de alto riesgo y $40 \%$ de las sepsis neonatales por SGB ocurren en hijos de madres con bajo riesgo.

Es por ello que actualmente, las recomendaciones de los expertos son realizar detección de portadoras. Con esta medida, en E.U.A. se ha logrado reducir la sepsis neonatal precoz por SGB en $70 \%$. La experiencia del Hos- 
pital Clínico de la Universidad Católica con esta estrategia de prevención ha sido publicada por Abarzúa et $\mathrm{al}^{4}$. Realizando cultivo vaginal y rectal a 2.192 mujeres embarazadas durante el tercer trimestre de gestación, y utilizando dos medios de cultivo: uno corriente y otro selectivo (caldo Todd Hewitt), se encontró 19,8\% de portación. Usando sólo el medio de cultivo corriente se detecta $12 \%$ de portación. La experiencia previa del hospital, en que se usaba sólo cultivo vaginal y sólo medio corriente de cultivo, detectaba 5\% de portación. Con la nueva estrategia, se ha reducido la sepsis neonatal en $60 \%$.

\section{Listeria monocytogenes}

Esta bacteria se encuentra ampliamente distribuida en la naturaleza, en la tierra, vegetales, y es parte de la flora fecal de muchos mamíferos. La adquisición por el hombre ocurre a través de la ingestión de alimentos contaminados (vegetales, leche y derivados, aves, carnes, etc). La infección en individuos sanos puede ser asintomática o presentarse como una gastroenteritis. En pacientes inmunodeprimidos y mujeres embarazadas ocurren sin embargo, formas severas como bacteriemia, meningitis y endocarditis. El diagnóstico se realiza mediante cultivos de sangre, LCR y líquido amniótico.

La infección en la mujer gestante ocurre más frecuentemente durante el tercer trimestre y suele presentarse con bacteriemia. Los síntomas son fiebre, mialgias, artralgias, cefalea, dolor lumbar; la meningitis es excepcional. La bacteria prolifera ampliamente en la placenta infectando al feto. Éste tiene riesgo de muerte fetal, que ocurre en $22 \%$ de los casos, debido a una infección fetal generalizada, llamada granulomatosis infantoséptica. Si el feto sobrevive y nace, el recién nacido está en riesgo de desarrollar una sepsis precoz generalmente asociada a prematurez, o una sepsis tardía. Ambas se manifiestan con alteraciones de la termorregulación, distress respiratorio y meningitis.

La terapia recomendada en el embarazo es ampicilina, a dosis altas, igualmente en el recién nacido ${ }^{5}$.

Las medidas preventivas de listeriosis incluyen:

- No comer carne cruda o mal cocida.

- Lavado cuidadoso de frutas y vegetales.

- Mantener la carne cruda lejos de otros alimentos.

- No consumir leche no pasteurizada.

En las mujeres embarazadas e inmunodeprimidos se agregan:
- Evitar el consumo de quesos blandos (tipo Camembert, Roquefort, etc.).

- Evitar consumo de hot dogs y otras comidas rápidas.

- Evitar el consumo de delicatessen (o cocinarlas antes de consumir).

\section{Chlamydia trachomatis}

La prevalencia de esta infección en mujeres embarazadas varía entre 2 y $37 \%$ en distintas series. En Chile, se ha encontrado 5\% de portación en mujeres gestantes y $35 \%$ en mujeres que se atienden en centros de ETS. El diagnóstico se puede realizar a través del cultivo, que es el patrón de oro tradicional. Esta técnica tiene baja sensibilidad (70-85\%) y sólo está disponible en centros muy especializados. En los últimos años se han desarrollado otras técnicas constituyendo el llamado patrón de oro expandido ${ }^{6}$. Aquí se incluyen técnicas inmunológicas, como IFD o ELISA y técnicas moleculares. La IFD tiene una sensibilidad entre 60 y $93 \%$ y una especificidad entre 94 y $99 \%$. Entre las técnicas moleculares se cuenta la hibridación con sondas, de poco uso actual (sensibilidad de 77 a 95\% y especificidad de 98\%) y técnicas de amplificación de material genético como RPC y otras. La RPC tiene una sensibilidad entre 75 y $97 \%$ y una especificidad mayor al $99 \%$.

La infección por C. trachomatis puede producir en la mujer procesos inflamatorios pelvianos (PIP), uretritis, salpingitis, embarazos ectópicos, infertilidad y endometritis post parto. En el hijo puede provocar la muerte fetal, partos prematuros, retardo del crecimiento intrauterino (RCIU), o cuadros de conjuntivitis o neumonía, entre la segunda y cuarta semana de vida.

La transmisión al hijo ocurre principalmente durante el parto, en especial en parto vaginal (transmisión 50-70\%), menos frecuentemente en cesárea con RPM (transmisión 20\%). Se han reportado casos anecdóticos de transmisión en cesáreas con membranas íntegras ${ }^{7}$.

En el manejo de la infección por $C$. trachomatis se recomienda el screening anual de las mujeres menores de 25 años sexualmente activas y de las mayores de 25 años con factores de riesgo. La terapia recomendada es azitromicina $1 \mathrm{~g}$ por una vez o doxiciclina $100 \mathrm{mg}$ cada 12 horas durante 7 días. Terapias alternativas son: eritromicina $500 \mathrm{mg}$ cada 6 horas, ofloxacina 300 $\mathrm{mg}$ cada 12 horas, levofloxacina $500 \mathrm{mg}$ al día, todos durante 7 días.

La terapia de elección en la mujer embarazada es eritromicina o amoxicilina durante 7 días. Alternativas son eritromicina mitad dosis diaria de durante 14 días o azitromicina en dosis única. 


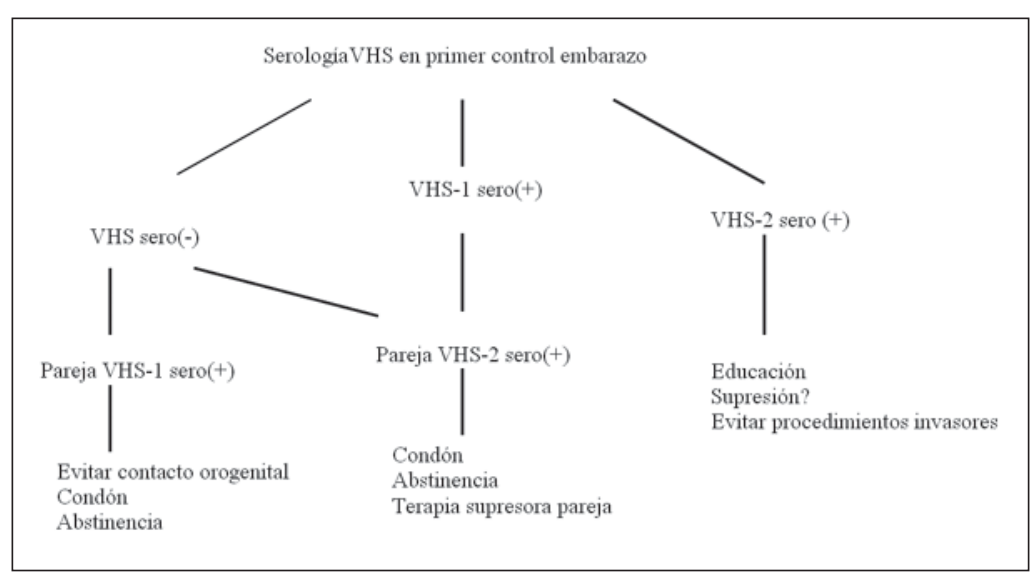

Figura 1. Algoritmo para la prevención y control de herpes genital en embarazo. rre después de las 20 semanas, puede causar parto prematuro, RCIU, o herpes neonatal. Esta condición clínica tiene tres formas de presentación, las dos primeras de elevada mortalidad y secuelas: herpes diseminado y encefalitis herpética o infección localizada en piel, ojo y boca.

\section{Manejo del primer episo- dio de herpes genital en la mujer embarazada ${ }^{8}$}

Se recomienda terapia con

En el embarazo están contraindicadas doxiciclina, ofloxacina, levofloxacina y eritromicina estolato. Azitromicina se considera segura en el embarazo. Debe controlarse 3 semanas después de terminado el tratamiento por posibles reinfecciones, $y$ siempre estudiar y tratar a la pareja.

\section{Herpes genital}

La prevalencia de herpes simplex genital o tipo 2 (VHS-2) en mujeres embarazadas varía entre 7 y $33 \%$ en distintas series. La prevalencia ha experimentado un sostenido aumento durante los últimos años. Se estima que aproximadamente 1 a $3 \%$ de las mujeres adquiere cada año la infección. En el caso de parejas discordantes, la tasa de adquisición aumenta hasta 10 a $30 \%$ anual. La adquisición durante el embarazo es $\sim 2 \%$.

La transmisión al hijo ocurre principalmente cuando la mujer embarazada adquiere una infección primaria. La transmisión es de 30 a 50\% cuando la infección primaria ocurre cerca del momento del parto. La mayor transmisión (85\%) ocurre durante el parto. Sin embargo, también puede ocurrir transmisión intrauterina $(5-8 \%)$ y post-natal (8-10\%). Los factores que inciden en la transmisión son: infección primaria mucho mayor eficiencia que infección recurrente, parejas discordantes, títulos de anticuerpos maternos y procedimientos obstétricos invasores, (los que están absolutamente contraindicados).

Las manifestaciones en la mujer embarazada son principalmente bajo la forma de herpes genital localizado, muy raramente ocurre diseminación cutánea y visceral, situación de elevada mortalidad (50\%). La infección en el niño, si ocurre en las primeras 20 semanas del embarazo, puede provocar aborto en $25 \%$, malformaciones cerebrales, cicatrices, corioretinitis, RCIU. Si ocu- aciclovir oral que reduce los síntomas, principalmente el dolor. Si ocurre herpes diseminado la terapia debe ser por vía endovenosa (reduce la mortalidad materna). Siempre debe intentarse dilucidar si se trata de un herpes primario o recurrente (mediante cultivo y serología). Si se trata de un herpes primario en un embarazo de más de 34 semanas, debe realizarse cesárea.

\section{Manejo del herpes recurrente en el embarazo ${ }^{8}$}

No se recomienda profilaxis con aciclovir, ni cultivo semanal para detectar excreción viral, puesto que esto no predice el riesgo del RN. Si existen lesiones en el momento del parto, la indicación de cesárea es relativa, y debe discutirse con la madre, indicando los riesgos de la cesárea y los costos, dado que no existen estudios controlados que demuestren la eficacia del parto quirúrgico.

Como forma de prevención del herpes genital en el embarazo, los expertos han recomendado estudio serológico de la mujer y su pareja, en forma de establecer los riesgos e indicar medidas preventivas. La Figura 1 muestra un algoritmo recomendado de prevención y control.

\section{Varicela}

Alrededor de 0,2\% de las mujeres embarazadas contraen la varicela durante este período. Estas cifras son mayores en países tropicales, donde la infección suele ser más tardía. Los riesgos para la madre son desarrollar una varicela severa o presentar neumonía varicelatosa, que tiene una mortalidad de $40 \%$ sin terapia ${ }^{9}$. El riesgo para el hijo depende del momento en que ocurra la infección. En el primer trimestre del embarazo el niño puede desarrollar varicela congénita; en el segundo trimestre, nacer con cicatrices de diversa cuantía; en el período periparto, 
presentar varicela diseminada. En cualquiera de estas situaciones, el niño tiene además riesgo de presentar herpes zoster en forma precoz (primer año de vida).

Varicela congénita. Ocurre cuando la madre adquiere la infección en las primeras 20 semanas de embarazo. La frecuencia es de alrededor de 2 a $3 \%$. El niño puede presentar cicatrices de piel, hipoplasia de extremidades, atrofia muscular localizada, microcefalia, retardo mental, cataratas, corioretinitis, microftalmia ${ }^{9}$.

Varicela perinatal. Ocurre cuando la madre presenta varicela entre 5 días antes y 2 días después del parto. El recién nacido presentará la infección después del período de incubación, esto es, entre los 5 y 10 días de vida. Por recibir una alta tasa de virus vía transplacentaria sin anticuerpos maternos, el recién nacido tiene riesgo de desarrollar formas graves de la infección, como son varicela diseminada y encefalitis, con una mortalidad de $30 \%$.

El diagnóstico de varicela generalmente es clínico. Ante lesiones dudosas se puede realizar detección de antígenos mediante IFD directa o cultivo tomado por hisopado del fondo de la lesión. El diagnóstico de inmunidad se realiza por detección de IgG específica.

\section{Profilaxis post-exposición ${ }^{9}$}

Se refiere al manejo de la mujer embarazada sin historia de varicela, con exposición a un enfermo. Inicialmente debe determinarse el grado de exposición, considerándose relevante un contacto cercano, como el intra-domiciliario. Debe confirmarse rápidamente la susceptibilidad de la mujer mediante IgG específica. Si la IgG es positiva la mujer es inmune y no tiene riesgo. $\mathrm{Si}$ es negativa, la mujer es susceptible. En esta situación está recomendado el uso de inmunoglobulina hiperinmune anti-varicela (VZIG), prioritariamente si la mujer está en las primeras 20 semanas de embarazo. La eficacia protectora de esta medida se estima en $70 \%$, puede prevenir o atenuar la infección, pero no está claro si previene la varicela congénita. La dosis es $125 \mathrm{U}$ (una ampolla) cada $10 \mathrm{~kg}$ de peso vía intramuscular (máximo $625 \mathrm{U}$ ) durante los primeros 4 días post-exposición. Otra alternativa, en la que no existe acuerdo entre los expertos por la escasa información disponible en cuanto a su eficacia, es el uso de aciclovir oral por 7 días iniciado entre 7 y 9 días post-exposición.

\section{Terapia de la mujer embarazada con varicela}

Si la mujer presenta neumonía varicelatosa debe recibir aciclovir endovenoso $(10 \mathrm{mg} / \mathrm{kg}$ cada
8 horas durante 7 días). La terapia con aciclovir oral está recomendada en la mujer embarazada con varicela durante el segundo y tercer trimestre debido a que alrededor de $20 \%$ presentan complicaciones. La dosis recomendada es 800 mg 5 veces al día durante 7 días iniciado idealmente en las primeras 24 horas del exantema. No existe consenso en las recomendaciones para trayar la varicela en mujeres durante el primer trimestre del embarazo. Algunos expertos recomiendan igual terapia que en los otros períodos del embarazo.

El uso de aciclovir en la gestación debe realizarse balanceando los riesgos y los beneficios. $\mathrm{Si}$ bien el fármaco no está licenciado para su uso en el embarazo, no existen evidencias de efecto teratogénico derivado de su uso. El mayor estudio incluyó 1.207 mujeres en distintas etapas del embarazo, no evidenciándose aumento de defectos congénitos. No está claro si su uso es capaz de evitar la varicela congénita, pues no se han realizado estudios controlados con número suficiente de casos. Aún no existen suficientes datos que avalen el uso de valaciclovir o famciclovir durante el embarazo.

\section{Parvovirus B19}

Alrededor de $1 \%$ de las mujeres embarazadas adquiere esta infección. La transmisión fetal ocurre en un tercio de los casos y el riesgo de muerte fetal se ha estimado en 9\%. En Chile, la susceptibilidad de mujeres en edad fértil se estima en $40 \%$ en el nivel socioeconómico bajo y de $50 \%$ en el alto $^{10}$.

La infección no tiene mayor riesgo para la madre y suele ser asintomática. En cambio, el feto está expuesto a desarrollar aplasia de los eritroblastos, células que el virus infecta produciendo su depleción; si ella es severa provocará una insuficiencia cardiaca secundaria a anemia intensa, pudiendo conducir a un edema generalizado conocido como hidrops fetal. Esta infección es la primera causa de hidrops fetal no inmune. La anemia del feto es posible corregirla mediante transfusiones intrauterinas. Aparentemente parvovirus no produce malformaciones congénitas, por lo que si se logra manejar la anemia, tendrá un buen pronóstico.

\section{Resumen}

La mujer embarazada está expuesta a contraer una variedad de infecciones, tanto bacterianas, como virales y parasitarias, muchas de las cuales implican un riesgo de afectar también al feto y 
recién nacido. La transmisión de infecciones de la madre al hijo (transmisión vertical) puede ocurrir tanto durante el embarazo como durante el parto y aún después del parto.

Este artículo resume ciertas medidas preventivas de probada eficacia contra algunas de estas infecciones, como son la vacunación pre- embarazo contra rubéola, varicela, hepatitis $\mathrm{B}$, difteriatétanos; o contra influenza durante el embarazo, el estudio serológico de algunas infecciones que cuentan con medidas de prevención de transmisión al hijo (VIH, sífilis, hepatitis B en no vacunadas) y medidas generales para prevenir la toxoplasmosis. Además revisa con mayor detalle las siguientes infecciones: Streptococcus b hemolítico Grupo B, Listeria monocytogenes, Chlamydia trachomatis, herpes genital, varicela y parvovirus. Para cada una de éstas se indican algunos aspectos epidemiológicos, frecuencia y momento de la transmisión vertical, los riesgos para la madre y para el hijo, las medidas terapéuticas para la infección materna y en especial, las medidas preventivas de la transmisión vertical.

\section{Bibliografía}

1. Brabin B. Epidemiology of infections in pregnancy. Rev Infect Dis 1985; 7 (5): 579-603.

2. CDC. Sexually transmitted diseases treatment guidelines
2002. MMWR Morbid Mortal Wkly Rep 2002; 51 (RR-6): 1-77.

3. CDC. Prevention of neonatal Group B Streptococcal disease. Revised guidelines from CDC. MMWR Morbid Mortal Wkly Rep 2002; 51: RR-11: 11-28.

4. Abarzúa F, Guzmán A M, Belmar C et al. Prevalencia de colonización por Streptococcus agalactiae (grupo B) en el tercer trimestre del embarazo. Evaluación del cultivo selectivo. Experiencia en 2.192 pacientes. Rev Chil Obstet Ginecol 2002; 67 (2): 89-93.

5. Cisternas A, Lagos N, Galstuch J, González C, García C, Díaz J. Infección por Listeria monocytogenes y embarazo con buen resultado perinatal. Rev Chil Obstet Ginecol 2002; 67 (3): 237-41.

6. Martínez M A. Diagnóstico microbiológico de Chlamydia trachomatis: Estado actual de un problema. Rev Chil Infectol 2001; 18: 275-84.

7. Valdés E, Juárez G, Almendras H, Caballero R. Chlamydia trachomatis: transmisión vertical con membranas íntegras. Rev Chil Obstet Ginecol 2002; 67 (1): 63-5.

8. Pass R, Weber T, Whitley RJ. Herpesvirus infections in pregnancy. Recommendations from the International Herpes Management Forum. Management Strategies Workshop and $7^{\text {th }}$ Annual Meeting.

9. Whitley R J. Varicella - Zoster virus. Mandell, Douglas and Bennett's Principles and Practice of Infectious Diseases. Mandell G, Bennett J, Dolin R, editors. Fifth edition, 2000 Churchill Livingstone, Philadelphia, pp: 1586-98.

10. Abarca K, Cohen B J, Vial P. Seroprevalence of parvovirus B19 in urban Chilean children and young adults, 1990 and 1996. Epidemiol Infect 2002; 128: 59-62. 